\title{
A Study on Knowledge, Attitude and Practice on Hypertension in Patients Who Suffered from Stroke Admitted in Tertiary Care Hospital
}

\author{
Md. Abdullah-Al-Maruf \\ Department of Medicine, 250 Bedded Hospital, Moulvibazar, Bangladesh
}

Email address:

mmhaque16rmc@yahoo.com

\section{To cite this article:}

Md. Abdullah-Al-Maruf. A Study on Knowledge, Attitude and Practice on Hypertension in Patients Who Suffered from Stroke Admitted in Tertiary Care Hospital. Science Journal of Clinical Medicine. Vol. 9, No. 4, 2020, pp. 102-107. doi: 10.11648/j.sjcm.20200904.13

Received: November 27, 2020; Accepted: December 24, 2020; Published: December 31, 2020

\begin{abstract}
Introduction: Hypertension is a crucial health problem and chronic disease in both developed and underdeveloped countries. Without prevention and treatment it may lead to life threatening complication of vital organs and patient's disability. Objective: Assessing patient's knowledge, their attitude and lifestyle practices on hypertension who suffered from stroke was the primary objective. The secondary objectives were to assess the compliance of hypertensive patients, their beliefs and misconceptions, awareness and practices on hypertension and the demographic and personal characteristics of the participants. Materials \& methods: This cross sectional observational study conducted in Dhaka Medical College Hospital and Shaheed Suhrawardy Medical College Hospital involving 100 adult patients who were hypertensive for at least 2 years and presented with stroke confirmed by CT scan of brain. Data was collected by structured questionnaire. Part of the questionnaire was taken from 'WHO STEP wise approach' to chronic disease surveillance which was translated into Bengali for better understanding. Chi- square test was used to analyze the data with a significance level of $p<0.05$. Results: Maximum numbers of hypertensive patient who suffered from stroke were between 45-54 years (41\%). Minimum age 38 years and maximum age 80 years, mean age 52.02 \pm 8.26 (SD) years. Male patients were $55(55 \%)$ and female 45 (45\%) \& male: female was 1.2:1 Mean systolic and diastolic blood pressure were $156.07 \pm 16.61$ (SD) and $89.84 \pm 9.78$ (SD) mm of Hg respectively. Sixty percent (60\%) of the study population had knowledge on hypertension and (49\%) had knowledge on the risk factors. Tobacco smoking (100\%) and lack of physical activity (95.9\%) were identified as the common risk factors. Patients who reported to be doing physical exercise were (57\%) and smoking (26\%). Irregular antihypertensive was taken by $(30 \%)$ of the patients and (33\%) could not mention about the medication. Conclusion: A vast majority of the hypertensive patients still have poor knowledge on hypertension, risk factors, and lifestyle practices. It is necessary to implement effective educational strategies directed towards the patients and public so that they can avoid the risk factors, hence reducing the prevalence of hypertension.
\end{abstract}

Keywords: Hypertension, Stroke, Risk Factors

\section{Introduction}

Hypertension (HTN) is defined as blood pressure (BP) $\geq 140 / 90 \mathrm{~mm} \mathrm{Hg}$, at least two readings on separate occasions [1]. Common risk factors as per literature include age, sex $(\mathrm{M}>\mathrm{F})$, ethnic group, fatty diet [2], cholesterol [3], carbohydrate and salt, stress, sedentary lifestyle, degree of urbanization [4], family history, diabetes mellitus, preexisting vascular diseases [5]. The Seventh Report of the Joint National Committee on the Prevention, Detection, Evaluation, and Treatment of High Blood Pressure (JNC 7) classified HTN as normal, pre-hypertension, and stages 1 and 2 hypertension. Each stage of hypertension was described by BP patterns, the presence or absence of cardiovascular risk factors, early markers of hypertensive CVD, and target organ damage. According to JNC 7, BP levels $<120 / 80 \mathrm{~mm} \mathrm{Hg}$ were classified as "normal", $\mathrm{BP} \geq 120 / 80$ to $<140 / 90 \mathrm{~mm} \mathrm{Hg}$ were "pre-hypertension" [6].

Stroke is defined as rapidly developing symptoms and/or signs of focal and at times global loss of cerebral function lasting for $24 \mathrm{hrs}$ or more with no apparent cause other than that of vascular origin [7]. It is the cause of one in eight 
deaths and constitutes a formidable burden of disability in the community [8]. Stroke is the leading cause of long-term adult disability and the fifth leading cause of death in the US, with approximately 795,000 stroke events in the US each year [9]. A good number of stroke patients are admitted in the secondary, tertiary and super specialized hospitals in Bangladesh. Some of them die in hospitals and a significant number survive with disability rendering economical and social burdens on the family and society.

Hypertension is the leading modifiable risk factor for stroke, being causally involved in nearly $(70 \%)$ of all stroke cases [10]. Nearly (48\%) percent of all patients with stroke report a history of arterial hypertension [11] and up to three fourth of those with known and treated hypertension are not adequately controlled. A meta-analysis of 17 randomized, controlled trials demonstrated a $(38 \%)$ reduction of stroke by controlling high BP [12]. This observation creates opportunities for population-based strategies of BP control to produce a substantial relief in the global burden of stroke. Hypertension is two types- primary (essential) and secondary. Essential hypertension has a multifactorial etiology such as genetic factors, fetal factors, environmental factors, humoral mechanisms and insulin resistance. Secondary hypertension occurs due to renal, endocrine, and cardiovascular pathology, drugs and pregnancy induced hypertension [1]. Stroke, myocardial infarction and cardiovascular death cause mortality associated with high blood pressure [13]. In 2004, an estimated 55,000 deaths were directly attributed to hypertension, and it was considered an underlying or contributing factor in at least another 300,000 [14].

Awareness, treatment, and control of hypertension are still not optimum. Two-third of hypertensive patients are aware of their status, meaning that a large segment of the population has unrecognized and untreated hypertension. Controlling these risk factors have a significant impact on the morbidity and mortality rates to acceptable levels. In hypertensive subjects, awareness about their increased risk for stroke is connected to higher compliance in stroke prevention practices [15].

Assessment of knowledge, attitudes, and practices is the key element of hypertension control strategies, but little information is available from developing countries where hypertension has lately been recognized as a major health problem. This study primarily focused on these issues.

\section{Materials and Methods}

It was a cross-sectional observational study done in the medicine ward of Dhaka Medical College Hospital and Shaheed Suhrawardy Medical College Hospital involving 100 Patients who were hypertensive for at least 2 years and clinically presented with features of stroke confirmed by CT scan. Patients who were diagnosed as stroke but with normal blood pressure, hypertension for less than 2 years, unconscious or could not communicate were excluded. Patients attending the above mentioned hospital and meeting the inclusion criteria were enrolled by a simple random sampling technique. The operational definitions followed in this study were 'Knowledge'- any ideas about hypertension, 'Attitude'- feelings and beliefs regarding hypertension, and 'Practice'- activities that were related to hypertension and were usually done by the respondents. At first written informed consent was taken and structured questionnaire were filled up after admission of the patient. Part of the questionnaire was taken from 'WHO STEP wise approach' to chronic disease surveillance which was translated into Bengali version for better understanding of the patients. The data collected were analyzed with Statistical Package for Social Sciences (SPSS) 17.0 software. Percentages and proportions were used to describe categorical variables while mean and standard deviation were used for numerical variables. Chi-square test was used to analyze the difference between variables as appropriate. $\mathrm{p}<0.05$ was taken as indicating statistical significance. Ethical clearance was taken from the proper authority prior to the protocol setting.

\section{Results}

Table 1 shows that among the 100 respondents maximum number of hypertensive patients who suffered from stroke were in the age group of 45-54years (41\%). Mean age $52.02 \pm 8.26$ (SD) years, minimum age 38 years and maximum age 80 years. Male population was $55(55 \%)$ and female $45(45 \%) \&$ male: female $=1.2: 1$ Table 2 .

Table 1. Age distribution of study population (n=100) Data presented as number (\%).

\begin{tabular}{llll}
\hline Age in years & Male & Female & Total \\
\hline $35-44$ & $7(7 \%)$ & $6(6 \%)$ & $13(13 \%)$ \\
$45-54$ & $17(17 \%)$ & $24(24)$ & $41(41 \%)$ \\
$55-64$ & $17(17 \%)$ & $13(13 \%)$ & $30(30 \%)$ \\
$65-74$ & $12(12 \%)$ & $2(2 \%)$ & $14(14 \%)$ \\
$75-84$ & $1(1 \%)$ & $1(1 \%)$ & $2(2 \%)$ \\
Total & $55(55 \%)$ & $45(45 \%)$ & $100(100 \%)$ \\
\hline
\end{tabular}

Table 1 showing maximum number of hypertensive patient who suffered from stroke was in the age group of 45-54years (41\%) followed by 55-64 yrs (30\%).

Table 2. Sex distribution of study population $(n=100)$ Data presented as number (\%).

\begin{tabular}{ll}
\hline Sex Distribution & Frequency (\%) \\
\hline Male & $55(55 \%)$ \\
Female & $45(45 \%)$ \\
Total & $100(100 \%)$ \\
\hline
\end{tabular}

Table 2 showing male population was 55(55\%) and female population $45(45 \%) \&$ ratio of male: female $=1.2: 1$

Among the study population, majority belonged to average socioeconomic background $80(80 \%)$ whereas $12(12 \%)$ were poor Table 3. Majority of the respondents were admitted with hemorrhagic stroke 55(55\%) Table 4. Regarding smoking status, 26(26\%) were present smoker, 57(57\%) were nonsmoker and the rest were past smokers $17(17 \%)$ Table 5. 
Table 3. Socio-economic status of study population ( $n=100)$ Data presented as number (\%).

\begin{tabular}{ll}
\hline Status & Frequency (\%) \\
\hline Rich & $8(8 \%)$ \\
Average & $80(80 \%)$ \\
Poor & $12(12 \%)$ \\
\hline
\end{tabular}

Table 3 showing majority were of average socioeconomic background $(80 \%),(12 \%)$ were poor and $(8 \%)$ were from higher socio-economic background.

Table 4. Type of stroke among the study population Data presented as number (\%).

\begin{tabular}{ll}
\hline Type & Frequency (\%) \\
\hline Hemorrhagic & $55(55 \%)$ \\
Ischemic & $43(43 \%)$ \\
SAH & $2(2 \%)$ \\
\hline
\end{tabular}

Table 4 shows majority of the respondents were admitted with hemorrhagic stroke $(55 \%)$, while $(43 \%)$ were admitted with ischemic stroke and only $(2 \%)$ with sub-arachnoid hemorrhage.

Table 5. Smoking status of study population Data presented as number (\%).

\begin{tabular}{ll}
\hline Smoking Status & Number of patients (\%) \\
\hline Present Smoker & $26(26 \%)$ \\
Past Smoker & $17(17 \%)$ \\
Non-smoker & $57(57 \%)$ \\
\hline
\end{tabular}

Table 5 showing $(26 \%)$ respondents were present smoker while most of them were non-smokers $(57 \%)$ and the rest were past smokers $(17 \%)$.

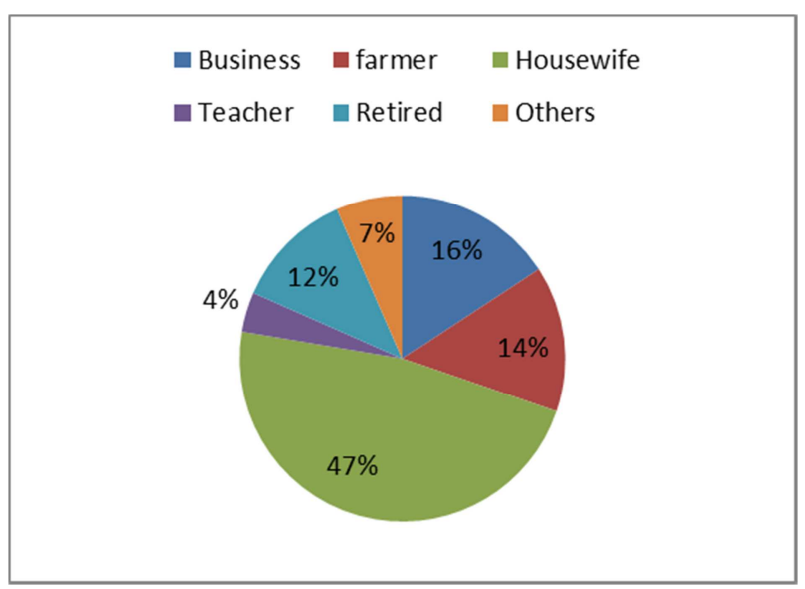

Figure 1. Occupation of study population.

Figure 1 shows the occupation of the enrolled patients where majority were housewives $47(47 \%), 16(16 \%)$ businessmen, $14(14 \%)$ farmers, $12(12 \%)$ retired from service, and the remainder from other occupations. This reflected that most of the women interviewed were housewives. In Figure 2 educational status of the patient is shown where most of the study patients were illiterate $39(39 \%)$, 33(33\%) completed up to school, 20(20\%) college and $8(8 \%)$ university education.

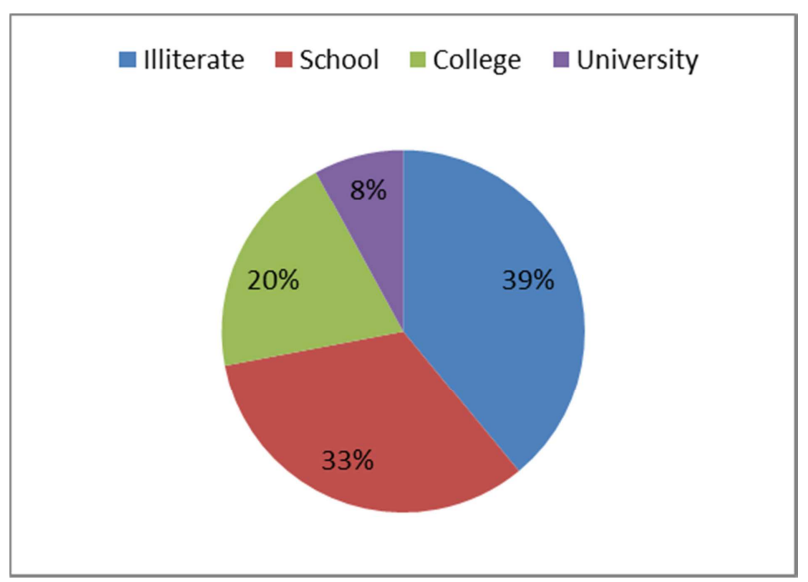

Figure 2. Educational background of study population.

Regarding knowledge of HTN in Table 6, 88(88\%) Respondents replied that an MBBS doctor told them about their HTN $\left(\mathrm{X}^{2} \mathrm{cal}=2.142 ; \mathrm{p}=0.126\right)$. While only $31(31 \%)$ mentioned that they were told about HTN by traditional healers $\left(X^{2}\right.$ cal $\left.=5.091 ; p=0.019\right)$. Majority $60(60 \%)$ had the understanding about persistence of HTN which is more in literate $42(68.9 \%$ ) than illiterate $18(46.2 \%)$, but a small portion were unaware of it $\left(\mathrm{X}^{2} \mathrm{cal}=9.17 ; \mathrm{p}=0.010\right)$. Less than half of the respondents $49(49 \%)$ had knowledge about the risk factors of HTN $\left(\mathrm{X}^{2} \mathrm{cal}=13.96 ; \mathrm{p}=0.000\right)$. among whom knowledge about smoking tobacco was 49(100\%), obesity $47(95.9 \%)$, and lack of physical activity $47(95.9 \%)$. Majority of the subjects $79(79 \%)$ had knowledge of lifestyle measures to control HTN $\left(\mathrm{X}^{2} \mathrm{cal}=2.001 ; \mathrm{p}=0.123\right)$ which was more in literates 51(64.6\%). Among them losing weight was mentioned to be more important in $73(92.4 \%)$ than mild regular exercise $67(84.8 \%$ ), and avoiding extra salt with food $65(82.3 \%)$. Regarding adverse outcome of HTN, most of the respondents focused on increased risk of stroke 90(90\%) $\left(X^{2} \mathrm{cal}=2.060 ; \mathrm{p}=0.138\right)$ rather than increased risk of heart disease $76(76 \%)\left(\mathrm{X}^{2} \mathrm{cal}=4.962 ; \mathrm{p}=0.024\right)$ and only $56(56 \%)$ $\left(\mathrm{X}^{2} \mathrm{cal}=2.516 ; \mathrm{p}=0.084\right)$ patients knew about the risk of kidney disease. Eighty two (82\%) participants knew about the lifelong treatment nature of HTN $\left(\mathrm{X}^{2} \mathrm{cal}=1.116\right.$; $\mathrm{p}=0.214$ ).

Table 6. Knowledge of hypertension in the study population.

\begin{tabular}{|c|c|c|c|c|}
\hline Variable & Yes & No & $\mathrm{X}^{2} \mathrm{cal}$ & p value \\
\hline \multicolumn{5}{|l|}{ 1. High blood pressure that } \\
\hline a. Always persist & $60(60 \%)$ & & & \\
\hline b. Occur sometimes & $11(11 \%)$ & & 9.166 & 0.010 \\
\hline 2. Hypertension is a lifelong disease & $72(72 \%)$ & $28(28 \%)$ & 3.471 & 0.052 \\
\hline 3. Whether knows about risk Factors Knowledge of those who answered 'yes'( $n=49)$ & $49(49 \%)$ & $51(51 \%)$ & 13.96 & 0.000 \\
\hline Tobacco smoking $* *$ & $49(100 \%)$ & $0(0 \%)$ & & \\
\hline
\end{tabular}




\begin{tabular}{|c|c|c|c|c|}
\hline Variable & Yes & No & $X^{2}$ cal & p value \\
\hline b. Obesity & $44(89.8 \%)$ & $5(10.2)$ & 0.001 & 0.733 \\
\hline c. Lack of physical activity & $47(95.7 \%)$ & $2(4.3 \%)$ & 1.124 & 0.370 \\
\hline 4. Knows about lifestyle measures to prevent HTN Knowledge of those who answered 'yes' - & $79(79 \%)$ & $21(21 \%)$ & 2.001 & 0.123 \\
\hline a. Avoid extra salt & $65(82.3 \%)$ & $14(17.7 \%)$ & 0.409 & 0.364 \\
\hline b. Loosing weight & $73(92.4 \%)$ & $6(7.6 \%)$ & 0.013 & 0.641 \\
\hline c. Mild regular exercise $67(84.8 \%)$ & & $12(15.2 \%)$ & 1.310 & 0.205 \\
\hline \multicolumn{5}{|l|}{ 5. Knowledge of complications } \\
\hline a. Incresed risk of stroke & $90(90 \%)$ & $10(10 \%)$ & 2.060 & 0.138 \\
\hline b. Increased risk of heart disease & $76(76 \%)$ & $24(24 \%)$ & 4.962 & 0.024 \\
\hline c. Increased risk of kidney disease & $56(56 \%)$ & $44(44 \%)$ & 2.516 & 0.084 \\
\hline 6. Hypertension needs lifelong treatment & $82(82 \%)$ & $18(18 \%)$ & 1.116 & 0.214 \\
\hline
\end{tabular}

$\mathrm{X}^{2}$ cal: chi square calculated , $\mathrm{p}$-value: probability value, ${ }^{*}$ no statistics was calculated because knowing tobacco smoking as a risk factor was a constant in the study population who answered 'yes' about knowing risk factors.

Regarding attitude and practices of hypertension in Table $7,66(66 \%)$ patients measured their BP within last 12 months, while $12(12 \%)$ patients did not measure within last 5 years $\left(X^{2} \mathrm{cal}=7.078 ; \mathrm{p}=0.029\right)$. Majority of the respondents took medicine within last two weeks $76(76 \%)\left(\mathrm{X}^{2}\right.$ cal $=1.319$; $\mathrm{p}=0.187$ ) with a good emphasis on reduced salt intake $79(79 \%)$, losing weight $66(66 \%)$ and doing exercise $57(57 \%)$. Slightly more than half of the study population reported to be doing physical exercises but the number of men $(70.6 \%)$ exercising was found to be more than twice than that of women $(29.94 \%)$. Twenty six (26\%) participants smoked tobacco products daily with a mean of $14.31 \pm 8.97$ (SD) per day. About half of the respondents $48(48 \%)$ took smokeless tobacco products such as snuff, chewing tobacco or betel etc. Among them 43(43\%) took smokeless tobacco products daily. The study population consumed fruits and vegetables with a mean of $2.32 \pm 0.723$ (SD) and $5.26 \pm 1.26$ (SD) days/ week respectively. A few patients 14(14\%) were taking herbal or traditional remedy for HTN during the study period. All the respondents 100(100\%) used soya bean oil for cooking. Only 19(19\%) participants underwent vigorous intensity activity as part of their work while 33(33\%) underwent moderate intensity activity. Unfortunately $30(30 \%)$ respondents took irregular anti-hypertensive medication and $33(33 \%)$ respondents could not mention the name of medication.

Table 7. Attitude and practices of hypertension in the study population.

\begin{tabular}{|c|c|c|c|c|}
\hline Variable & Yes & No & $\mathrm{X}^{2} \mathrm{cal}$ & p-value \\
\hline \multicolumn{5}{|l|}{ 1. BP last measured by an MBBS doctor } \\
\hline a. Within 12 months & $66(66 \%)$ & & & \\
\hline b. Within $1-5$ years & $22(22 \%)$ & & 7.708 & 0.029 \\
\hline c. Not within 5 years & $12(12 \%)$ & & & \\
\hline \multicolumn{5}{|l|}{ 2. Whether following doctor's advice } \\
\hline a. Taken medication within 2 wks & $76(76 \%)$ & $24(24 \%)$ & 1.319 & 0.187 \\
\hline b. Reduced extra salt with food & $79(79 \%)$ & $21(21 \%)$ & 0.166 & 0.434 \\
\hline d. Doing exercise & $57(57 \%)$ & $43(43 \%)$ & 1.789 & 0.129 \\
\hline 3. Ever seen a traditional healer & $9(9 \%)$ & $91(91 \%)$ & 0.123 & 0.494 \\
\hline 4. Currently taking herbal/traditional medication & $14(14 \%)$ & $86(86 \%)$ & 0.828 & 0.267 \\
\hline 5. Smokes any cigarette/cigars & $26(26 \%)$ & $74(74 \%)$ & 0.013 & 0.551 \\
\hline a. Those who answered 'yes' Smokes cigarette/cigars daily & $26(100 \%)$ & $0(0 \%)$ & $*$ & $*$ \\
\hline 6. Smoked daily in the past & $41(41 \%)$ & $59(59 \%)$ & 1.554 & 0.150 \\
\hline 7. Currently use smokeless tobacco (snuff, betels etc) & $48(48 \%)$ & $52(52 \%)$ & 0.276 & 0.374 \\
\hline 9. Work involves moderate activity & $33(33 \%)$ & $67(67 \%)$ & 4.177 & 0.124 \\
\hline 10. Knows name of medicine & $67(67 \%)$ & $33(33 \%)$ & 8.0122 & 0.331 \\
\hline
\end{tabular}

$\mathrm{X}^{2}$ cal: chi square calculated, p-value: probability value, *no statistics was calculated because respondents who smokes cigarette/cigars smoke daily.

\section{Discussion}

Among the study population (60\%) had knowledge on hypertension but $(49 \%)$ on the risk factors. Similar findings were observed in study done in Africa where Burkina Faso populations were not well-known about hypertension and cardiovascular risk factors [16]. Physical exercise was done by more than half $(57 \%)$ of the study population where the number of men $(70.6 \%)$ were more than women $(29.94 \%)$ which was similar to the study done by Nothwehr F, et al.
[17]. Percentage of the studied patients who smoked was $(26 \%)$. This showed that men were exposed to risk factors of hypertension more than women.

The study showed that more than half of the patients (51\%) had poor knowledge about risk factors. Although the study was conducted in a clinical setting that included the patients with adverse outcome of HTN and other associated co-morbidities, this finding was not unexpected in view of the dysfunctional health system in the country where there was acute shortage of workforce with large population of 
patients and rarely any useful time to attend to patients meaningfully. A similar problem was also found in patients with other chronic diseases such as diabetes mellitus [18, 19]. However, data on patients' knowledge of their HTN are improving in other developing countries with similar epidemiological transition as in Bangladesh. Majority of the patients with good knowledge of HTN had at least a primary school education. This finding was not unexpected as the patients' level of education is generally known to have positive influence on their understanding of specific health education program and relevant behavior change techniques $[20,21]$. However, it is important to note that many patients still have a lopsided understanding of the aim of their treatment when a large portion $(40 \%)$ were unaware of the persistence of HTN. This obviously has a ready consequence in poor compliance, poor control of HTN and increased risk of morbidity and mortality [22, 23].

It was observed that patient's compliance regarding use of antihypertensive drugs was poor, $(30 \%)$ of the respondents took medicine irregularly while $(33 \%)$ could not mention about their medication. Only (19\%) participants underwent vigorous activity as part of their work while (33\%) underwent moderate intensity activity. These findings were almost similar to the reports of previous studies [24-27]. Poor compliance with medication was due to poor knowledge about the disease and the need for long-term treatment, illiteracy, and to some extent, use of alternative source of treatment.

Poor compliance with medications as well as antihypertensive lifestyle remains a crucial problem in the treatment of chronic asymptomatic diseases and is one of the most important reasons why HTN cannot be treated effectively [28, 29]. In this study we observed that compliance was negatively influenced by poor knowledge of HTN and antihypertensive drugs. Patient's level of education, skilled occupations and being health conscious have been previously shown to be associated with improved compliance among patients with HTN [30]. Although the issue of poor knowledge of HTN and compliance with antihypertensive lifestyle and drugs require a holistic approach that takes into consideration all the identified factors, there is need to invent and adopt new means of educating the public in general and the patients in particular [31].

There are huge scopes for improvement in patients' awareness and knowledge about hypertension, its consequences, and lifestyle modifications to control it. Moreover, it seems to be important to help patients transfer their knowledge adequately into practice. Perceived risk is one of the key factors for promoting behavioral changes; a person perceiving risk for some adverse event as high is more likely to take preventive action to reduce the risk [32]. For our patients, this could, for example, mean providing individualized risk feedback, which was shown to be effective in increasing perceived stroke risk among patients who had underestimated their stroke risk [32]. This study not only aimed at improving the knowledge of high risk population, but also increasing the awareness. Because the drugs for effective lowering of blood pressure exist, education of affected patients is an important target to convert the possible risk reduction into reality for all patients with hypertension.

\section{Conclusion}

It was observed that in our country patients' knowledge of HTN was inadequate, their attitude to treatment was not positive enough and their healthy lifestyle practices were grossly deficient. Effective strategies should be planned improving the level of knowledge through information, education, motivation and communication. This will help changing their wrong perceptions, particularly fear and the view of a chronic disease like HTN as an intermittent illness that requires ephemeral treatment. More large scale studies using standardized methods are suggested to comprehensively assess the HTN knowledge, attitudes and life-style practices of hypertensive population.

\section{References}

[1] Kumar P, Clark M. Kumar and Clarks Clinical Medicine. $5^{\text {th }}$ Edition. WB Saunders: Elservier Science Limited; 2002.

[2] Bener A, Al-Suwaidi J, Al-Jaber K, Al-Marri S, Dagash MH, Elbagi IEA, The prevalence of hypertension and its associated risk factors in a newly developed country. Saudi Med J. 2004; 25 (7): 918-922.

[3] Njelekela M, Negishi H, Nara Y, Tomohiro M, Kuga S, Noguchi T, et al, Cardiovascular risk factors in Tanzania: a revisit. Acta Trop. 2001; 79 (3): 231-239.

[4] Daniel HI, Rotimi CN. Genetic epidemiology of hypertension: an update on the African diaspora. Ethn Dis. 2003; 13 (2): 5366.

[5] Burket BA. Blood pressure survey in two communities in the Volta region, Ghana, West Africa. Ethn Dis. 2006; 16 (1): 292294.

[6] Chobanian AV, Bakris GL, Black HR, Cushman WC, Green LA, Izzo JJL, et al. The seventh report of the joint national committee on prevention, detection, evaluation, and treatment of high blood pressure: the JNC 7 report. JAMA. 2003; 289 (19): 2560-2572.

[7] Park JE, Park K. Stroke. Textbook of Preventive and Social Medicine. $15^{\text {th }}$ Edition. Jabalpur: M/S Banarsidas Bhanot Publisher; 1995. P. 245-246

[8] Boehme AK, Esenwa C, Elkind MSV. Stroke Risk Factors, Genetics, and Prevention. Circ Res. 2017; 120 (3): 472-495.

[9] Ralph SL. Pathogenesis, classification and epidemiology of cerebrovascular disease. In: Lewis P, Rowland, eds. Merit's Textbook of Neurology. $9^{\text {th }}$ Edition. Baltimore: Williams and Wilkins; 1995. P. 227-242.

[10] Kalkonde YV, Alladi S, Kaul S, Hachinski V. Stroke Prevention Strategies in the Developing World. Stroke. 2018; 49: 3092-3097. 
[11] Bornstein NM, Aronovich BD, Karepov VG, Gur AY, Treves TA, Oved MK, et al. The Tel Aviv stroke registry. 3600 consecutive patients. Stroke. 1996; 27 (10): 1770-1777.

[12] Chalmers J. Global burden of stroke. Heart Dis. 2000; 2 (2): S13-S17.

[13] Haslett C, et al. Davidson's Principles and Practice of Medicine. $19^{\text {th }}$ Edition. Churchill Livingstone: Harcourt Publishers Limited; 1999.

[14] Rosamond W, Flegal K, Furie K, Go A, Greenlund K, Haase $\mathrm{N}$, et al. Heart disease and stroke statistics 2008 update: a report from the American heart association statistics committee and stroke statistics subcommittee. Circulation. 2008; 117 (4); e25-e146.

[15] Samsa G, Cohen S, Goldstein L, Bonito A, Duncan P, Enarson $\mathrm{C}$, et al. Knowledge of risk among patients at increased risk for stroke. Stroke. 1997; 28: 916-921.

[16] Nothwehr F, Elmer P, Hannan P. Prevalence of health behaviors related to hypertension in three blood pressure treatment groups: the Minnesota heart health program. Prev Med. 1994; 23 (3): 362-368.

[17] Parker DR, Derby CA, Usner DW, Gonzales S, Lapane KL, Carleton RA. Self-reported alcohol intake using two different question formats in Southeastern New England. Int J Epidemiol. 1996; 25: 770-774.

[18] Famuyiwa OO, Edozien EM, Ukoli CO. Social, cultural and economic factors in the management of diabetes mellitus in Nigeria. Afr J Med Sci. 1985; 14 (3-4): 145-154.

[19] Fabiyi AK, Kolawole BA, Adefehinti O, Ikem RT. The impact of knowledge, attitude, practice and beliefs of type 2 Nigerian diabetic patients on drug compliance. Diab Int. 2002; 12 (1): $15-17$.

[20] Venkatesh U, Srivastava DK. Knowledge, Attitude and Practice in Relation to Stroke: Comparative Study between Hypertensive and Non-Hypertensive Patients Attending a Tertiary Care Centre in Gorakhpur, Uttar Pradesh, India. JMSCR. 2016; 4 (12): 15014-15021.

[21] Prochaska JO, Di Clemente C. Towards a comprehensive model of change. In: Miller W, Heather N, eds. Treating Addictive Behaviours: Processes of Change. New York: Plenum Press; 1986. p. 3-27.

[22] Kumar KGS, Gray AJ, AdarshAayiliath K3. Study on
Resistant Hypertension in a Tertiary Care Centre in Malabar. IOSR-JDMS. 2020: 19 (3): 39-43.

[23] O'Rorke JE, Richardson WS. What to do when blood pressure is difficult to control. BMJ. 2001; 322 (7296): 1229-1232.

[24] Bovet P, Burnier M, Madeleine G, Waeber B, Paccaud F. Monitoring one-year compliance to antihypertension medication in the Seychelles. Bull World Health Organ. 2002; 80 (1): 33-39.

[25] Moname M, Bohn RL, Gurwitz JH, Glynn RJ, Levin R, Avorn J. The effects of initial drug choice and comorbidity on antihypertensive therapy compliance: results from a population-based study in the elderly. Am J Hypertens. 1997; 10 (7 Pt 1): 697-704.

[26] Lee JY, Kusek JW, Greene PG, Bernhad S, Norris K, Smith D, et al. Assessing medication adherence by pill count and electronic monitoring in the African American study of kidney disease and hypertension (AASK) pilot study. Am J Hypertens. 1996; 9 (8): 719-725.

[27] Mengden T, Un S, Dusing R, Weisse B, Vetter H. Drug compliance decreases between clinic visits: the effect of white coat compliance on 24-hour ambulatory blood pressure monitoring. J Hypertens. 2000; 18 (Suppl 4): S169.

[28] Bertholet N, Favrat B, Fallab-Stubi CL, Brunner HR, Burnier M. Why objective monitoring of compliance is important in the management of hypertension. J Clin Hypertens. 2002; 2 (4): $258-262$.

[29] Rudd P. Clinicians and patients with hypertension: unsettled issues about compliance. Am Heart J. 1995; 130 (3 pt 1): 572579 .

[30] Hungerbuhler P, Bovet P, Shamlaye C, Burnand B, Waeber B. Compliance with medication among outpatients with uncontrolled hypertension in the Seychelles. Bull World Health Organ. 1995; 73 (4): 437-442.

[31] Gruninger UJ, Duffy FD, Goldstein MG. Patient education in the medical encounter: how to facilitate learning, behaviour change and coping. In: Lipkins M, Lazare A, Putnam S, eds. The Medical Interview. New York: Springer; 1994.

[32] Kreuter MW, Strecher VJ. Changing inaccurate perceptions of health risk: results from a randomized trial. Health Psychol. 1995; 14 (1): 56-63. 